\title{
FLORESCIMENTO E FRUTIFICAÇÃO DO MARACUJAZEIRO SILVESTRE Passiflora setacea D. C. CULTIVADO EM JABOTICABAL, SP'
}

\author{
ELMA MACHADO ATAIIDE², JOÃO CARLOS DE OLIVEIRA ${ }^{3}$ CARLOS RUGGIERO ${ }^{4}$
}

RESUMO - Muitas espécies de Passiflora apresentam comportamento florífero diferente durante o ano e, consequentemente, com variações nas produções e períodos de colheitas, como observado para o maracujazeiroamarelo (Passiflora edulis sims). Estudo com espécies silvestre constitui-se numa importante alternativa para usos de novos genótipos no melhoramento das espécies cultivadas comercialmente, em especial, a Passiflora setacea, devido ao grande potencial de mercado; contudo, essa espécie é pouco estudada, principalmente em relação à propagação, germinação, floração e condições de armazenamento. Assim, o objetivo deste trabalho foi avaliar o florescimento e a frutificação do maracujazeiro silvestre Passiflora setacea cultivado em Jaboticabal-SP. A floração e a frutificação foram avaliadas pelo percentual de frutificação através da polinização natural e artificial das flores, realizado no período de agosto a outubro. As características físicas dos frutos foram avaliadas através dos seguintes parâmetros: a) massa do fruto (g); b) diâmetro longitudinal do fruto $(\mathrm{cm})$; c) diâmetro transversal do fruto $(\mathrm{cm})$; d) espessura da casca $(\mathrm{cm})$; e) rendimento de polpa (\%). A característica química foi determinada por meio do teor de sólidos solúveis (SS). Verificou-se que a Passiflora setacea apresentou precocidade de floração em relação ao maracujazeiro-amarelo, com florescimento durante o ano todo, nas condições de Jaboticabal-SP. Observou-se que essa espécie possui bom nível de tolerância às doenças foliares, resistência à morte precoce e apresenta diferentes níveis de compatibilidade entre as plantas, possibilitando a essas características serem utilizadas em programas de melhoramento genético. Constatou-se ainda que as características físicas encontradas nos frutos atendem às exigências da indústria. Termos para indexação: floração, frutos, maracujá, polinização.

\section{FLOWERING AND FRUCTIFICATION OF WILD PASSION FRUIT Passiflora Setacea D. C. GROWN IN JABOTICABAL, SP}

\begin{abstract}
Passiflora species have flowering behavior varying along the year and, consequently with variation in production and harvest time, as observed in yellow passion fruit (Passiflora edulis sims). Studying wild species constitutes a very important alternative to diversify crop species, especially Passiflora setacea due to great national and international market potential, Nevertheless, studies with this species are scanty mainly concerning flowering and fructification. Therefore, the objective of this study was to evaluate the seeding, germination, flowering and storage conditions of Passiflora setacea wild passion fruit grown in Jaboticabal, SP. Flowering and fructification were assessed by fructification perceptual through natural and artificial pollination, from August to October, while disease occurrence was assessed in the field after planting. Physical fruit characteristics were evaluated by fruit mass (g), longitudinal and transversal diameter $(\mathrm{cm})$, peel thickness $(\mathrm{cm})$ and pulp yield $(\%)$. Chemical characteristic was determined by soluble solid content (SS). It was verified that Passiflora setacea presents flowering precocity related to yellow passion fruit, flowering all the year in Jaboticabal, SP conditions. Passiflora setacea has good level of foliar disease resistance, resistance to early death and presents different levels of plant compatibility, allowing its use in genetic improvement programs. It was also stated that fruit physical characteristics attend to industry requests. Index terms: flowering, fruits, passion fruit, pollination.
\end{abstract}

${ }^{1}$ (Trabalho 046-12). Recebido em : 04-01-2012. Aceito para publicação em: 30-05-2012.

${ }^{2}$ Dra.,Universidade Federal Rural de Pernambuco/Unidade Acadêmica de Serra Talhada, Serra Talhada-PE. E-mail: elmaataide@uast.ufrpe.br ${ }^{3}$ Dr., Faculdade de Ciências Agrárias e Veterinárias/Universidade Estadual Paulista, Jaboticabal-SP, E-mail: fitotecnia@fcav.unesp.br ${ }^{4}$ Dr., Faculdade de Ciências Agrárias e Veterinárias/Universidade Estadual Paulista, Jaboticabal-SP. E-mail: ruggiero@fcav.unesp.br 


\section{INTRODUÇÃO}

Das fruteiras com grande potencial de cultivo no Brasil, o maracujazeiro tem apresentado acentuada expansão, proporcionando grande popularização no mercado interno, nos diferentes segmentos de consumo. Apesar de a produção brasileira ser bastante significativa em relação aos outros países produtores de maracujá, o volume produzido é insuficiente para atender à demanda interna de frutos in natura, assim como de suco concentrado (BERNACCI et al., 2005). As espécies cultivadas comercialmente são a Passiflora edulis Sims (maracujazeiro-azedo e maracujazeiro-roxo) e a $P$. alata Curtis (maracujazeiro-doce). Independentemente da espécie, existem problemas fitossanitários que comprometem seu cultivo comercial. As doenças provocadas por patógenos do solo constituem-se nas mais importantes, em termos de expressão econômica (RUGGIERO, 2000), além da limitação de florescimento em algumas regiões, em alguns meses do ano.

Em vista do exposto, para garantir o mercado interno e possibilitar a exportação de suco concentrado de maracujá, é necessário o incremento da produção, especialmente em regiões onde há restrição à produção no período de setembro a novembro (entressafra), período que permite aos produtores auferirem preços altamente diferenciados. Estudos buscando aproveitar espécies resistentes nos programas de melhoramento, a variabilidade entre e dentro de espécies do gênero Passiflora para resistência a doenças e pragas têm sido feitos e caracterizados (RUGGIERO, 2000), assim como o manejo da floração com uso de reguladores vegetais e bioestimulante (ATAÍDE, 2005).

Entre as várias espécies silvestres no Brasil, algumas têm características interessantes que podem ser inseridas no maracujazeiro comercial, tanto com potencial para o mercado de fruta in natura, como na forma de sucos, doces e sorvetes. Além da importância medicinal, de acordo com Faleiro et al. (2008), deve-se às propriedades calmantes em algumas espécies, entre outras, que ainda são pouco conhecidas. A utilização para fins ornamentais também tem ganho bastante importância, além da riqueza oferecida pelas espécies nativas e pelas variedades silvestres. O maracujazeiro-sururuca ou maracujazeiro-do-sono (P. setacea D. C.) é uma espécie silvestre pouco estudada com relação à propagação, germinação, condições de armazenamento das sementes (MELETTI et al., 2002) e em relação à floração, polinização e caracterização de frutos. Vários autores (FISCHER et al., 2005; JUNQUEIRA et al., 2005; OLIVEIRA; RUGGIERO, 2005; SAN-
TOS et al., 2005; BRAGA et al., 2006) relatam que essa espécie possui tolerância a algumas doenças e pragas, com resistência à morte precoce e à fusariose, e de patógenos de doenças da parte aérea, como a antracnose (JUNQUEIRA et al., 2005), constituindo, assim, o $P$. setacea em excelente fonte de resistência genética a fitopatógenos que acometem a cultura do maracujazeiro. Além da resistência a doenças e algumas pragas, há algumas espécies que apresentam aspectos fenológicos relacionados ao florescimento bastante peculiares (JUNQUEIRA et al., 2005).

Verifica-se que, além dos aspectos comentados, observa-se o potencial da $P$. setacea para a incorporação no mercado consumidor, seja pelas suas propriedades medicinais, seja em função do seu potencial como fruta fresca, devido ao sabor exótico, doce e saboroso do fruto ou, ainda, na forma de doces e sorvetes.

As Passifloras são dependentes da polinização cruzada para a formação do fruto, devido a sua morfologia floral. Apesar de a flor ser completa em maracujazeiro-amarelo, ocorre autoincompatibilidade (BRUCKNER et al., 1995; SUASSUNA et al., 2003). Nesta espécie, a polinização influencia a frutificação, seja por ação de agentes polinizadores, seja através da polinização artificial, sendo a diferença do percentual de pegamento pelos dois métodos, segundo Oliveira e Ruggiero (2005), devido ao número de polinizadores presentes no local do cultivo. Diferentes espécies de maracujazeiro apresentam períodos de abertura floral distintos, quase sempre curtos, dificilmente com duração de oito horas. Nas condições de Jaboticabal, Oliveira e Ruggiero (2005) observaram abertura de flores de P. setacea após as 18 horas, com taxa de frutificação baixa, provavelmente, devido à ausência de agentes polinizadores. Foi, observado por Costa et al. (2009), que o melhor momento de coleta de grãos de pólen de $P$. setacea, com maior viabilidade, ocorre às $10 \mathrm{~h}$ 45 , no dia da antese.

Em vista do exposto, o objetivo do trabalho foi avaliar o florescimento e a frutificação do maracujazeiro silvestre Passiflora setacea cultivado em Jaboticabal, SP.

\section{MATERIAL E MÉTODOS}

O trabalho foi conduzido no Banco de Germoplasma (BAG) de maracujazeiro do Departamento de Fitotecnia da FCAV/UNESP, Jaboticabal-SP, situado sob as Coordenadas a $21^{0} 15^{\prime} 22^{\prime \prime}$ de latitude sul e $48^{\circ} 18^{\prime} 22^{\prime \prime}$ de longitude a oeste de Greenwich e altitude de $610 \mathrm{~m}$. A temperatura média anual é de $22^{\circ} \mathrm{C}$, a pluviosidade anual é de $1.440 \mathrm{~mm}$, e a 
umidade relativa, de 70,8\%. O solo é classificado como Latossolo Roxo.

Para a realização do estudo, foram utilizadas seis plantas de Passiflora setacea D. C., conduzidas no BAG/FCAV. Na época da instalação do experimento, os maracujazeiros apresentavam bom desenvolvimento vegetativo, conduzidos em espaldeira vertical, com dois fios de arame a $1,80 \mathrm{~m}$ do solo. Já o comportamento dos maracujazeiros, quanto à ocorrência a doenças em condições de campo, foi acompanhado desde o plantio. Os tratos culturais e adubação foram os convencionais adotados para a cultura do maracujazeiro na região.

O comportamento dos maracujazeiros em relação à floração e à frutificação foi avaliado pelo percentual de frutificação, através da polinização natural e artificial das flores, nos meses de agosto a outubro, enquanto o período da floração foi acompanhado durante todo o ano. Nesse período, foram identificados e protegidos com saco de papel branco os botões florais, às $17 \mathrm{~h} 30$, um dia antes da abertura floral, para impedir a visita de insetos polinizadores, além da identificação das que foram visitadas por polinizadores (polinização natural). A polinização artificial das flores identificadas foi realizada pela manhã, às $7 \mathrm{~h}$, e à tarde, às $17 \mathrm{~h} 30$.

As características físicas dos frutos foram avaliadas no Laboratório do Departamento de Fitotecnia da FCAV/UNESP, através de mensurações em amostras de 30 frutos colhidos por planta após a abscisão. Foram avaliados os seguintes parâmetros: a) massa do fruto $(\mathrm{g})$; b) diâmetro longitudinal do fruto; c) diâmetro transversal do fruto (cm); d) espessura da casca $(\mathrm{cm})$; e) rendimento de polpa $(\%)$. O tamanho do fruto foi obtido medindo-se o diâmetro longitudinal, com auxílio de paquímetro, desde a inserção do pedúnculo até a cicatriz do estigma, e o diâmetro transversal, na região equatorial do fruto. A massa do fruto foi determinada utilizando-se de balança digital analítica. A espessura da casca foi medida com o mesmo paquímetro. $\mathrm{O}$ rendimento de polpa foi obtido através da fórmula: $\%$ rendimento de polpa (massa dos frutos e massa das cascas) x100/ massa dos frutos.

As características químicas foram determinadas por meio do teor de sólidos solúveis (SS), utilizando-se de refratômetro digital manual Atago, com resultado expresso em ${ }^{\circ}$ Brix.

\section{RESULTADOS E DISCUSSÃO}

Verificou-se, nas condições do presente estudo, a ocorrência de flores em maracujazeiro-do-sono (P. setacea D. C.) durante todo o ano, inclusive no período de junho a setembro, meses em que não ocorre o florescimento do maracujazeiro-amarelo.

Observou-se a abertura das flores a partir das 17h 30 e maior número de flores nos meses de julho e agosto. Resultados semelhantes foram observados por Santos et al. (2005), conduzindo estudo com a mesma espécie nas condições do Distrito Federal. Tal resultado apresentado possibilitará o uso dessa espécie, em programa de melhoramento do maracujazeiro comercial, tendo em vista que a espécie em estudo floresce em dias curtos e, principalmente, quando aliado às boas características físicas e químicas dos frutos.

Conforme dados apresentados na Tabela 1, verificou-se, nesta espécie, o percentual de frutificação natural baixo, com apenas 3,33\%. Contudo, quando realizada a polinização artificial das flores, principalmente à tarde, no dia da antese floral, observou-se maior frutificação $(63,64 \%)$. Pode-se considerar esse período o melhor para realizar a polinização, assim como para se realizarem hibridações manuais em programas de melhoramento do P. setacea. Costa et al. (2009) observram, para $P$. alata Curtis, que o melhor momento para a coleta de pólen foi às $10 \mathrm{~h} 45$, no dia da antese.

Em relação à polinização das flores, a maior percentagem de frutificação foi obtida com a polinização artificial, podendo o baixo percentual de frutificação natural encontrado no referido trabalho ser influenciado por diferentes níveis de compatibilidade entre plantas nesta espécie, ou, ainda, segundo Oliveira e Ruggiero (2005), devido à ausência de agentes polinizadores.

Observou-se que o período do florescimento à colheita de $P$. setacea foi de 50 a 36 dias, cujos frutos, quando maduros, apresentaram aroma agradável, semelhante ao "abacaxi", enquanto, imaturos, o aroma de "fruto verde". O formato do fruto foi ovalado, casca com presença de listas esverdeadas, sementes de coloração leitosa e a polpa de sabor agradável, doce acidulado e bastante apreciada na forma de suco.

Quanto às características físicas dos frutos, as médias encontradas para os diâmetros longitudinal e transversal foram de $5,47 \mathrm{~cm}$ e $3,79 \mathrm{~cm}$, respectivamente. Essas variáveis são importantes, pois determinam o formato do fruto; já que frutos oblongos apresentam cerca de $10 \%$ a mais de suco em relação aos de formato redondo; atendendo, as- 
sim, à indústria, conforme reportado por Fortaleza et al. (2005). Já Santos et al. (2005), observaram nesta espécie frutos de formato redondo-ovalado.

Em relação à massa dos frutos $(\mathrm{g})$, a média encontrada foi de $46,10 \mathrm{~g}$, e a espessura da casca, de $0,33 \mathrm{~cm}$. Já o rendimento médio de polpa dos frutos foi de $34,52 \%$ (Tabela 2). Resultados encontrados por Santos et al. (2005) foram superiores aos encontrados, no presente trabalho, tanto para a massa do fruto $(47,26 \mathrm{~g})$, como para o rendimento de polpa $(53,6 \%)$; tais variáveis encontradas em ambos os trabalhos, atendem às exigências da indústria. Em relação ao teor de sólidos solúveis encontrados nos frutos, os resultados foram semelhantes aos obtidos por Santos et al. (2005), nas condições do Distrito Federal (Tabela 2).

Observou-se, nas condições de campo, que as plantas $P$. setacea apresentaram resistência à morte precoce das plantas, conforme observado nesta espécie pelos autores Fischer (2005), Junqueira et al. (2005), Oliveira e Ruggiero (2005), Santos et al. (2005), Braga et al. (2006), assim como observado por Junqueira et al. (2005), quanto à boa tolerância às doenças foliares, como a antracnose.

TABELA 1- Médias do percentual (\%) de frutificação com uso da polinização artificial e natural das flores de Passiflora setacea. Jaboticabal-SP, 2011.

\begin{tabular}{|c|c|c|c|}
\hline \multirow[b]{2}{*}{ Número de flores } & \multicolumn{3}{|c|}{ POLINIZAÇÃO NATURAL } \\
\hline & Frutificação & Fruti & icação(\%) \\
\hline \multirow[t]{2}{*}{30} & 01 & & 3,33 \\
\hline & \multicolumn{3}{|c|}{ POLINIZAÇÃO ARTIFICIAL } \\
\hline $\begin{array}{l}\text { Polinização } \\
\text { Manhã }\end{array}$ & Número de flores & Frutificação & Frutificação (\%) \\
\hline $\begin{array}{l}\text { Com proteção das flores } \\
\text { (Progenitor masc.e fem.) }\end{array}$ & 11 & 02 & 18,18 \\
\hline $\begin{array}{l}\text { Sem proteção das flores } \\
\text { (Progenitor masc. e fem.) }\end{array}$ & 20 & 02 & 10,00 \\
\hline $\begin{array}{l}\text { Polinização } \\
\text { Tarde }\end{array}$ & Número de flores & Frutificação & Frutificação (\%) \\
\hline $\begin{array}{l}\text { Com proteção das flores } \\
\text { (Progenitor masc. e fem.) }\end{array}$ & 47 & 11 & 23,40 \\
\hline $\begin{array}{l}\text { Sem proteção das flores } \\
\text { (Progenitor masc. e fem.) }\end{array}$ & 11 & 07 & 63,64 \\
\hline
\end{tabular}

TABELA 2 - Médias da massa do fruto, diâmetros longitudinal e transversal, espessura da casca, rendimento de polpa e sólidos solúveis em frutos de Passiflora setacea. Jaboticabal-SP, 2011.

\begin{tabular}{ccc}
\hline Parâmetros & Médias & CV (\%) \\
\hline Massa do fruto $(\mathrm{g})$ & 46,10 & 43,17 \\
Diâmetro longitudinal do fruto $(\mathrm{cm})$ & 5,47 & 14,75 \\
Diâmetro transversal do fruto $(\mathrm{cm})$ & 3,79 & 17,48 \\
Espessura da casca (cm) & 0,33 & 34,12 \\
Rendimento de polpa (\%) & 34,52 & - \\
Sólidos solúveis ( ${ }^{\circ}$ Brix) & 16,52 & 15,06 \\
\hline
\end{tabular}




\section{CONCLUSÃO}

Os resultados obtidos permitem antever que o Passiflora setacea apresenta características importantes, cuja prospecção genética deve ser priorizada, para fins de melhoramento voltado à resistência genética a fitopatógenos que acometem a cultura do maracujazeiro.

\section{REFERÊNCIAS}

ATAIDE, E.M. Indução floral e produtividade do maracujazeiro-amarelo em função do uso de reguladores de crescimento vegetal. 2005 . $88 \mathrm{f}$. Tese (Doutorado em Produção Vegetal)- Faculdade de Ciências Agrárias e Veterinárias, Universidade Estadual Paulista, Jaboticabal, 2005.

BERNACCI, L.C; MELETTI, L.M.M.; SOARESSCOTT, M.D.; PASSOS, I.R.S.; JUNQUEIRA, N.T.V. Espécies de maracujá: caracterização e conservação da biodiversidade. In: FALEIRO, F.G.; JUNQUEIRA, N. T.V.; BRAGA, M.F. (Org.). Maracujá: germoplasma e melhoramento genético. Planaltina: Embrapa Cerrados, 2005. p. 559-586.

BRAGA, M.F.; SANTOS, E.C.; JUNQUEIRA, N.T.V.; SOUSA, A.A..T.C.; FALEIRO, F.G.; REZENDE, L.N.; JUNQUEIRA, K.P. Enraizamento de estacas de três espécies silvestres de Passiflora. Revista Brasileira de Fruticultura, Jaboticabal, v. 28, n. 1, p. 284-288, 2006.

BRUCKNER, C.H.; CASALI, V.W.D.; MORAES, C.F.; REGAZZI, A. J.; SILVA, E. A.M. Selfincompatibilidade in passion fruit (Passiflora edulis Sims). Acta Horticulturae, The Hague, v. 370, p. 45-57, 1995.

COSTA, R.S.; MÔRO, F.V.; OLIVEIRA, J.C.de. Influência do momento de coleta sobre a viabilidade de grão de pólen em maracujá-doce (Passiflora alata Curtis). Revista Brasileira de Fruticultura. Jaboticabal, v. 31, n. 4, p. 956-961, 2009.

FALEIRO, F.G.; JUNQUEIRA, N.T.V.; BRAGA, M.F. Pesquisa e desenvolvimento do maracujá no Brasil. In: SILVA, A.G.; ALBUQUERQUE, A.C.S.; MANZANO, N.T.; SILVA, R.C.; RUSSELL, N.C. (Ed.). Agricultura tropical: quatro décadas de inovações tecnológicas, institucionais e políticas. Brasília: Embrapa, 2008.
FISHER, I.H.; LOURENÇO, S.A.; MARTINS, M.C.; KIMATI, H.; AMORIM, L. Seleção de plantas resistentes e de fungicidas para o controle da podridão do colo do maracujazeiro causada por Nectria haematococca. Fitopatologia Brasileira, Brasília, v.30, n.3, p.250-258, 2005.

FORTALEZA, J.M.; PEIXOTO, J.R.; JUNQUEIRA, N.J.V.; OLIVEIRA, A.T.; RANGEL, L.E.P. Características físicas e químicas em nove genótipos de maracujá-azedo cultivada sob três níveis de adubação potássica. Revista Brasileira de Fruticultura. Jaboticabal, v. 27, n. 1, p. 124-127, 2005.

JUNQUEIRA, N.T.V.; BRAGA, M.F.; FALEIRO, F.G.; PEIXOTO, J.R.; BERNACCI, L.C. Potencial de espécies silvestres de maracujazeiro como fonte de resistência a doenças. In: FALEIRO, F.G.; JUNQUEIRA, N.T.V.; BRAGA, M.F. (Org.). Maracujá: germoplasma e melhoramento genético. Planaltina: Embrapa Cerrados, 2005. p.81-106.

MELETTI, L.M.M.; FURLANI, P.R.; ÁLVARES, V.; SOARES-SCOTT, M.D.; BERNACCI, L.C.; FILHO, J.A.A. Novas tecnologias melhoram a produção de mudas de maracujá. O Agronômico, Campinas, v. 54, p.30-33, 2002.

OLIVEIRA, J.C.; RUGGIERO, C. Espécies de maracujá com potencial agronômico. In: FALEIRO, F. G.; JUNQUEIRA, N. T. V.; BRAGA, M. F. (Ed.). Maracujá: germoplasma e melhoramento genético. Planaltina: Embrapa Cerrados, 2005. p.143-158.

RUGGIERO, C. Situação do maracujazeiro no Brasil. Informe Agropecuário, Belo Horizonte, v. 21, p. 5-9, 2000.

SANTOS, F.C.; RAMOS, J.D.; SANTOS, F.C.; LIMA, L.C.O. de; JUNQUEIRA, K. P.; REZENDE, J.C. da. Características físico-químicas do maracujazeiro silvestre Passiflora setacea. In: REUNIÃO TÉCNICA DE PESQUISAS EM MARACUJAZEIRO, 4., 2005, Planaltina. Anais... Planaltina: Embrapa Cerrados, 2005. p. 143-146.

SUASSUNA, T.M.F.; BRUCKNER, C.H.; CARVALHO, C.R.; BOREMA, A. Self-incompatibility in passionfruit: evidence of gametophytic-sporophytic control. Theoretical and Applied Genetics, Berlin, v. 106, n. 2, p. 298-302, 2003. 